Erratum to: Automatic Fall Detection Using Membership Based Histogram Descriptors. JOURNAL OF COMPUTER SCIENCE AND TECHNOLOGY DOI 10.1007/s11390-018-1815-6

\title{
Erratum to: Automatic Fall Detection Using Membership Based Histogram Descriptors
}

Erratum: Mohamed Maher Ben Ismail and Ouiem Bchir. Automatic Fall Detection Using Membership Based Histogram Descriptors. Journal of Computer Science and Technology 2017, 32(2): 356-367. DOI 10.1007/s11390017-1725-z.

In "Acknowledgement", the name of the funding institution should be King Saud University, instead of King South University. 